\title{
Bone Marrow Transplantation only Partially Restores Purine Metabolites to Normal
} in Adenosine Deaminase-deficient Patients

\author{
Rochelle Hirschhorn, Vivienne Roegner-Maniscalco, and Lloyd Kuritsky, \\ Department of Medicine, New York University School of Medicine, \\ New York 10016 \\ Fred S. Rosen, Department of Pediatrics, Harvard Medical School, Boston, \\ Massachusetts 02115
}

\begin{abstract}
A B S T R A C T To delineate the extent to which bone marrow transplantation provides "enzyme replacement therapy", we have determined metabolite concentrations in two patients with adenosine deaminase (ADA) deficiency treated with bone marrow transplants and rendered immunologically normal. $10 \mathrm{yr}$ after engraftment of lymphoid cells, erythrocyte deoxy ATP was markedly decreased compared to the marked elevations of deoxy ATP observed in untreated patients, but was still significantly elevated (62 and $90 \mathrm{vs}$. normal of $6.0 \pm 6.0 \mathrm{nmol} / \mathrm{ml}$ packed erythrocytes). Similarly, deoxyadenosine and adenosine excretion were both markedly diminished compared to that of untreated patients but deoxyadenosine excretion was still clearly increased (20.1 and 38.6 vs. normal of $<0.2 \mathrm{nmol} / \mathrm{mg}$ creatinine) while adenosine excretion was in the upper range of normal (7.0 and $8.1 \mathrm{vs.} \mathrm{normal}$ of $5.6 \pm 3.6 \mathrm{nmol} / \mathrm{mg}$ creatinine). Mononuclear cell deoxy ATP content was also elevated compared to normal (5.25 and 14.4 vs. $1.2 \pm 0.3$ ). Separated mononuclear cells of bone marrow transplanted patients contain both donor lymphocytes and recipient monocytes. When mononuclear cells were depleted of the patients' own monocytes, the deoxy ATP content of the cells enriched for donor lymphocytes (i.e. monocyte depleted) was lower than that of the mixed mononuclear cells (2.2 vs. 5.26). Surprisingly, plasma adenosine was as high as in untreated ADA-deficient patients (3.2 and 1.5 vs. untreated of $0.3-3 \mu \mathrm{M}$ ). Consistent with the elevated plasma adenosine and
\end{abstract}

\footnotetext{
Portions of this work were presented in part at the $92 \mathrm{nd}$ Annual Meeting of the Association of American Physicians and was published in abstract form in 1979. Clin. Res. 27: 507a.

Received for publication 10 September 1980 and in abstract form 6 July 1981 .
}

urinary deoxyadenosine, erythrocyte $S$-adenosyl homocysteine hydrolase activity was diminished (0.88 and 1.02 vs. normal of $5.64 \pm 0.25)$.

Thus, bone marrow transplantation of ADA-deficient patients not only provides lymphoid stem cells, but also partially, albeit incompletely, clears abnormally increased metabolites from nonlymphoid body compartments.

\section{INTRODUCTION}

Inherited deficiency of the purine salvage enzyme, adenosine deaminase (ADA), ${ }^{1}$ results in the fatal infantile syndrome of severe combined immunodeficiency (ADA-SCID) (1-3). Affected children accumulate the purine nucleoside substrates of ADA adenosine, deoxyadenosine, and their phosphorylated metabolites (4-12). Accumulation of such metabolites presumably results in lymphospecific toxicity, by one or more proposed mechanisms $(7,13-17)$.

Children with $\mathrm{ADA}^{-} \mathrm{SCID}$ can be returned to normal immunologic function by transplantation of bone marrow from a related histocompatible donor. The ease of engraftment and subsequent immunologic reconstitution of ADA-deficient patients has not differed appreciably from that of non-ADA-deficient SCID, although cells other than lymphoid cells remain ADA-deficient (18).

Immunologic reconstitution following bone marrow transplantation is generally presumed to result from

\footnotetext{
${ }^{1}$ Abbreviations used in this paper: ADA, adenosine deaminase; DCF, deoxycoformycin; HPLC, high pressure liquid chromatography; PCA, perchloric acid; SAH hydrolase, $S$-adenosyl homocysteine hydrolase; SCID, severe combined immunodeficiency.
} 
the engraftment of normal lymphoid stem cells. However, the engrafted lymphoid progenitor cells and their mature offspring would also appear to provide "enzyme therapy" in patients with ADA deficiency. Thus, Chen et al. (19) have reported that bone marrow transplantation is also followed by clearing of one abnormal metabolite, deoxy (d) ATP, from the patient's own, still ADA-deficient erythrocytes. In order to more fully delineate the extent to which "enzyme replacement therapy" is provided by engraftment of normal lymphoid cells, we have now determined concentrations of additional metabolites in several body fluids and cells of two ADA-deficient, bone marrow transplanted, immunologically normal children.

\section{METHODS}

Materials. Nucleosides were purchased from Sigma Chemical Co. St. Louis, Mo. or P-L Biochemicals (Milwaukee, Wis.); DNA polymerase from Worthington Biochemicals Corp., Freehold, N. J.; calf thymus DNA and calf intestinal ADA, type 1, from Sigma Chemical Co.; and $\left[{ }^{14} \mathrm{C}\right]$ deoxy cytidine triphosphate from Amersham Corp., Arlington Heights, Ill., and poly (dA-dT) from P-L Biochemicals. Waters Associates Inc., Milford, Mass. supplied the reverse phase $\mathrm{C}_{18} \mu$ Bondapack column and Bio-Rad Laboratories, Richmond, Calif. supplied the AG 1-X2 anion exchange resin.

Urinary nucleosides. Urine (stored frozen at $-70^{\circ} \mathrm{C}$ with $0.01 \%$ azide) was defrosted, warmed briefly and a 3-ml aliquot removed, diluted to $10 \mathrm{ml}$ with $\mathrm{H}_{2} \mathrm{O}$, brought to $\mathrm{pH} 10.0$ and chromatographed on an anion exchange column (Bio-Rad, AG 1-X2) as described by Kuttesch et al. (10). The fraction containing adenosine was lyophilized, reconstituted with $\mathrm{H}_{2} \mathrm{O}$ and analyzed by "reverse phase" high-pressure liquid chromatography (HPLC) as previously described (9) using a $\mathrm{C}_{18} \mu$ Bondapack Column and a $0-40 \%$ linear gradient of $0.01 \mathrm{M}$ ammonium phosphate (pH 5.5) and methanol, generated over $60 \mathrm{~min}$ with a $1.5 \mathrm{ml} / \mathrm{min}$ flow rate. Adenosine and deoxyadenosine were identified by retention times, coelution with the authentic compounds, disappearance after incubation with exogenous ADA $(0.12 \mathrm{IU} / \mathrm{ml}$ for $2 \mathrm{~h}$ at $37^{\circ} \mathrm{C}$ ), the appearance of, or increase in a peak with the retention time of inosine and/or deoxyinosine and the 250/260 UV ratios of the substrates and products. Uric acid and creatinine were determined in the diluted and undiluted urine.

Erythrocyte and mononuclear cell dATP. Erythrocyte dATP was determined as previously described (9) using a DNA polymerase-dependent assay based upon the method of Solter and Handschumacher (21). The erythrocytes were extracted with perchloric acid (PCA) and freon/amine (22). Mononuclear cells were separated from freshly drawn heparinized blood by centrifugation on Hypaque Ficoll. The interface (which contains monocytes and platelets as well as lymphocytes) was diluted 1:1 with cold phosphate-buffered saline and centrifuged at $800 \mathrm{~g}$ for $15 \mathrm{~min}$. The cell pellet was gently resuspended at $\sim 10-15 \times 10^{6} / \mathrm{ml}$ phosphatebuffered saline, an aliquot removed for determination of cell number and the cells immediately pelleted in a Beckman microfuge (Beckman Instruments, Inc., Cedar Grove, N. J.) by centrifugation at $4^{\circ} \mathrm{C}$ for $1 \mathrm{~min}$.

Preliminary experiments indicated that methanol extracts of mononuclear cells, as reported for HeLa F' cells (23), used dADP and dAMP as well as dATP in a polymerase assay. PCA extraction of the methanol extract eliminated utilization of the mono- and dinucleotides. Recovery experiments indicated that a 5 min extraction with PCA followed by extraction with freon/amine resulted in $\sim 80-90 \%$ recovery of added dATP while reducing utilization of dADP to $<10 \%$ of methanol extracts. Longer extractions with PCA resulted in poorer recoveries. Cells were therefore extracted and assayed for dATP content essentially by this slight modification of the method of North et al. (23) using a shorter time for PCA extraction. In brief, the cell pellet was resuspended in $1 \mathrm{ml} 60 \%$ methanol, vortexing vigorously for $1-3 \mathrm{~min}$ at $4^{\circ} \mathrm{C}$ and kept at $-20^{\circ} \mathrm{C}$ for $36 \mathrm{~h}$. After centrifugation in a Beckman microfuge, the methanol extract was removed, brought to dryness under a stream of nitrogen, resuspended in $100 \mu \mathrm{l} \mathrm{H}_{2} \mathrm{O}$ and immediately extracted with $50 \mu \mathrm{l} 2.1 \mathrm{~N} \mathrm{PCA}$ for $5 \mathrm{~min}$ at $4^{\circ} \mathrm{C}$ and then extracted with freon/amine (22). The extract was again brought to dryness, resuspended in $30 \mu \mathrm{l}$ of $\mathrm{H}_{2} \mathrm{O}$ and assayed for dATP content using poly dA-dT as described by North et al. (23) and Escherichia coli DNA polymerase. The extracts did not significantly utilize dADP or dAMP and there was a linear increase in dATP with increasing extract volume in the assay, extrapolating to a "blank" identical with the reagent blank.

Determination of total deoxyadenosine containing compounds in mononuclear cells was performed based on the method described by Hershfield et al. (24). Mononuclear cells were prepared as described above, the cell pellet frozen at $-70^{\circ} \mathrm{C}$ and then directly extracted with PCA-freon/amine (22). To $180 \mu \mathrm{l}$ of neutralized extract was added $40 \mu \mathrm{l}$ of $0.5 \mathrm{M}$ Tris buffer, $\mathrm{pH}$ 8.0, containing $20 \mu \mathrm{M}$ erythro-9-(2hydroxy-3-nonyl)adenine (EHNA), and $10 \mu \mathrm{l}$ of bovine intestinal alkaline phosphatase containing $1 \mathrm{U}$ (type VII $\mathrm{S}$-Sigma Co.). The mixture was incubated for $1 \mathrm{~h}$ at $37^{\circ} \mathrm{C}$ and the reaction terminated by addition of $40 \mu \mathrm{l} 2.1 \mathrm{~N}$ PCA and neutralized with $40 \mu \mathrm{l} 2.21 \mathrm{~N} \mathrm{KOH}$. The supernatant was then analyzed for deoxyadenosine by HPLC on a $C_{18}$ $\mu$ Bondapak column (9). Preliminary experiments indicated that under these conditions, dAMP, dADP and dATP were totally converted to deoxyadenosine, but that no other reaction products were seen. The sensitivity was such that $10 \mathrm{pmol}$ of deoxyadenosine could easily be detected in the presence of 50,000 pmol of adenosine. In analysis of cell extracts, the identity of the peak eluting with the retention time of deoxyadenosine was confirmed by collecting the peak, drying under nitrogen, incubating with calf intestinal ADA and determining the amount of deoxyinosine (as identified by retention time and 250/260 ratios) generated.

Plasma nucleosides. Plasma adenosine and deoxyadenosine were determined as described (9). In brief, immediately after venepuncture, plasma was rapidly separated from whole blood by centrifuging in a Beckman microfuge at $4^{\circ} \mathrm{C}$ for 1-2 min and an equal volume of cold methanol was immediately added to the plasma. The mixture was kept at $4^{\circ} \mathrm{C}$, vortexed several times during $30 \mathrm{~min}$ and centrifuged for 3-5 $\mathrm{min}$ in a microfuge. The supernatant extract was then brought to dryness under nitrogen, reconstituted with $\mathrm{H}_{2} \mathrm{O}$, chromatographed on the anion exchange column and further processed and analyzed essentially as described for urine samples. (The normal plasma extract was sometimes concentrated twice as much as was the patients before HPLC in order to increase the lower limit of detection). In some experiments, blood was drawn into a syringe containing the tight binding ADA inhibitor deoxycoformycin (DCF). We determined that plasma extracts which contained DCF required incubation with $14.7 \mathrm{IU} \mathrm{ADA} / \mathrm{ml}$ for $2 \mathrm{~h}$ at $37^{\circ} \mathrm{C}$ to allow deamination of adenosine and deoxyadenosine when the plasma extract was incubated with ADA. DCF has a markedly shorter retention time than deoxyadenosine or adenosine, and can be separated from the two compounds by HPLC (retention time relative to adenosine $=0.67$ ). DCF also 
has a markedly lower area/pmol at $260 \mathrm{nmol}$. For experiments with $\left[{ }^{14} \mathrm{C}\right.$ ]adenosine, $3.755 \mathrm{ml}$ of freshly drawn heparinised blood was added to $245 \mu \mathrm{l}$ of a solution containing $4 \mathrm{nmol}$ of $\left[{ }^{14} \mathrm{C}\right]$ adenosine (sp act $=567 \mu \mathrm{C} / \mu \mathrm{M}$; Amersham) and 4 or 8 $\mathrm{nmol}$ of DCF. The erythrocytes and buffy coat were separated from the plasma as above and each then immediately extracted with PCA-freon/amine. The extract was chromatographed on DE 81 paper as described by Coleman (25). The areas migrating with AMP and ATP, hypoxanthine and inosine and adenosine, were then counted in a Beckman liquid scintillation counter. All other areas of the chromatogram were also counted and contained $₹ 2 \%$ of the total radioactivity.

S-adenosyl homocysteine (SAH) hydrolase activity. SAH hydrolase activity of erythrocytes was measured by determining the rate of synthesis of SAH from adenosine and homocysteine (20). Washed erythrocytes were diluted with an equal volume of water and dialyzed for $75 \mathrm{~min}$ at $4^{\circ} \mathrm{C}$ against two changes of 250 volumes of $0.05 \mathrm{M}$ phosphate buffer, $\mathrm{pH}$ 7.5. The dialyzed lysate was further diluted to a final concentration of 7-30 mg hemoglobin $/ \mathrm{ml}$. Aliquots of 20-100 $\mu \mathrm{l}$ were incubated with $1,000 \mu \mathrm{M}$ homocysteine and $10 \mu \mathrm{M}$ EHNA in a final volume of $210 \mu \mathrm{l}$ for $20-60 \mathrm{~min}$. The reaction was terminated by the addition of $100 \mu \mathrm{l} 2.2 \mathrm{~N}$ PCA and neutralized with $100 \mu \mathrm{l}$ of $2.21 \mathrm{~N} \mathrm{KOH}$. Aliquots were analyzed for SAH content by HPLC using the gradient system described for analysis of adenosine and deoxyadenosine. The reaction was linear in time and for varying concentrations of lysate. SAH eluted before adenosine with a retention time relative to adenosine of 0.86 . Adenine, inosine, AMP, and hypoxanthine had relative retention times of $0.7,0.5,0.4$ and 0.3 , respectively.

Patients. The case histories of both patients to age five and their erythrocyte ADA activity have been previously reported (18). They are currently both $10 \mathrm{yr}$ of age. All tests of immune functions are normal, as is their height, weight, and development. The patients' erythrocytes remain their own and are ADA-deficient, whereas both $\mathrm{B}$ and $\mathrm{T}$ lymphocytes are of donor origin and contain ADA. Monocytes would appear to have remained of recipient origin, as determined by the analysis for $\mathrm{Y}$ bodies in patient 1 . Mononuclear cell ADA (i.e. mixed lymphocytes and monocytes) of patient 1 is 194 $\mathrm{nmol} / \mathrm{mg}$ protein per $\mathrm{h}$, while that of his female sibling bone marrow donor is $424 \mathrm{nmol} / \mathrm{mg}$ protein per h. Normal mononuclear cell ADA by this method is $665 \pm 154(n=14)(24)$.

\section{RESULTS}

Erythrocyte dATP. Erythrocytes from both bone marrow transplanted patients contained increased dATP compared with normal (Table I). However, the erythrocyte dATP content of the bone marrow transplanted, ADA-deficient patients was markedly lower than that found in erythrocytes of untreated, ADAdeficient patients $(500-1,000 \mathrm{nmol} / \mathrm{ml}$ packed erythrocytes) $(7,8,11)$. The heterozygous sibling bone marrow donor for patient 1 had erythrocyte dATP within the normal range (data not shown).

Mononuclear cell dATP. dATP content of mononuclear cells (mixed lymphocytes and monocytes) was also found to be increased compared with normals (5.4 and 14.4 vs. $1.19 \mathrm{pmol} / 10^{6}$ cells) (Table I). There are no reported values for dATP content of mononuclear cells in untreated ADA-deficient patients. However,
dATP content of mononuclear cells in an erythrocyte transfused patient has been reported as $770-1,760$ $\mathrm{pmol} / 10^{6}$ cells (27). In more frequently transfused patients, and with the methodology described here, we have determined a dATP content of 15 and $50 \mathrm{pmol} / 10^{6}$ mononuclear cells in erythrocyte transfused ADAdeficient patients. We additionally determined the total nonphosphorylated and phosphorylated deoxyadenosine content of mononuclear cells by degrading all deoxyadenosine nucleotides to deoxyadenosine and determining deoxyadenosine by HPLC. The mixed mononuclear cells of the bone marrow transplanted patients contained 8.6 and $21.4 \mathrm{pmol} / 10^{6}$ cells vs. normal of 1.0. Similar differences were obtained when values were expressed per milligram of protein.

Since monocytes appeared to be the patient's own, while lymphocytes were of donor origin, we determined dATP in the two different cell types of patient 1 . The donor lymphocyte enriched (i.e. monocyte depleted) cell population had a dATP content which was half that of the mixed mononuclear cell population ( 2.2 vs. 5.3 pmol per $10^{6}$ cells).

Urinary adenosine and deoxyadenosine. Both bone marrow transplanted children still excreted easily detectable concentrations of deoxyadenosine, (Table II), albeit $<10 \%$ of that excreted by untreated ADAdeficient patients $(300-1,000 \mathrm{nmol} / \mathrm{mg}$ creatinine) (6, 10, 11). Normal children excrete $<0.2 \mathrm{nmol}$ deoxyadenosine/mg creatinine. Both patients excreted concentrations of adenosine in the upper range of normal. These concentrations of adenosine were, however, lower than the concentrations of adenosine excreted by untreated patients (24-31 $\mathrm{nmol} / \mathrm{mg}$ creatinine) $(10,11)$. Similar results were obtained if the results were expressed relative to uric acid excretion (Table II).

Plasma adenosine and deoxyadenosine. Deoxyadenosine, which we have found in micromolar concentration in plasma of untreated ADA-deficient patients (9), could not be detected in the plasma of either of the bone marrow transplanted patients $(<0.2 \mu \mathrm{M})$. In contrast, plasma adenosine was in the micromolar range, as high as that found in plasma of untreated or erythrocyte transfused patients $(4,7,9,12)$ (Table II). Because the marked elevation of plasma adenosine was not consistent with the only minimal elevations of other metabolites, we considered the possibility that this apparent increase in plasma adenosine might in a sense be "artifactual". Thus, in vivo, plasma adenosine presumably represents an equilibrium state between purines produced and excreted by cells with active de novo purine biosynthetic pathways (such as hepatocytes) and uptake and metabolism by cells such as erythrocytes that have only a "salvage pathway" for purines. Plasma adenosine, once removed from the body and a continuing source of renewal, 
TABLE I

dATP Content

\begin{tabular}{lcc}
\hline \multicolumn{1}{c}{ Subjects } & Erythrocytes* $^{*}$ & Mononuclear cellst \\
\hline Normal $(n=3)$ & $6.0( \pm 6.0)$ & $1.19( \pm 0.34)$ \\
ADA $^{-}$ & & \\
$\quad$ Bone marrow transplanted & & 5.25 \\
$\quad$ Patient 1 & $62.0( \pm 10.6)$ & 14.40 \\
$\quad$ Patient 2 & $65.0 ; 114.0$ & $15.0-50.0^{\prime \prime}$ \\
Untreated & $500.0 \$$ & $770.0 ; 1,760.09$ \\
\end{tabular}

* Nanomoles per milliliter packed erythrocytes \pm SD.

† Picomoles $/ 10^{6}$ cells \pm SD.

$\S$ Values determined in this laboratory (9): see also references 7-9, 19, 27.

"Values for erythrocyte transfused patients (see text) and reference 27.

could still be rapidly taken up and metabolized by the normal red cells containing ADA, even in the brief interval required for separation of plasma from erythrocytes. Since erythrocytes of the bone marrow transplanted patients still lack ADA and are incapable of deaminating adenosine during processing, the ex vivo concentration of adenosine might more closely approximate the in vivo concentration in ADA-deficient patients than in normals. In order to mimic the conditions present in ADA-deficient patients, we withdrew venous blood from normals into a syringe containing DCF, a potent inhibitor of ADA. We found that adenosine in plasma obtained from two normal individuals without addition of DCF was 0.026 and $0.032 \mu \mathrm{M}$. When the blood was drawn into a syringe containing DCF (final concentration of 1-2 $\mu \mathrm{M}$ ) then plasma adenosine of three normal individuals was 10 times higher $(0.28,0.33$ and $0.32 \mu \mathrm{M})$. However, in preliminary experiments, even in the presence of these high concentrations of DCF, we found that we could not recover $\sim 80 \%$ of adenosine added to whole blood when adenosine content of the separated plasma was determined by HPLC. This "loss" was not due to metabolism following separation of plasma from erythrocytes, since $87-110 \%$ of adenosine added to separated plasma could be recovered as adenosine (data not shown). To determine if the $80 \%$ of the added adenosine "lost" from plasma had been deaminated, even in the presence of high concentrations of DCF, we added freshly drawn, heparinised blood to radiolabeled adenosine and DCF (final concentrations of $1 \mu \mathrm{M}$ adenosine and 1 or $2 \mu \mathrm{M}$ DCF, separated the

TABLE II

Adenosine and Deoxyadenosine in Urine and Plasma of ADA-deficient Children, Bone Marrow Transplanted vs. Untreated

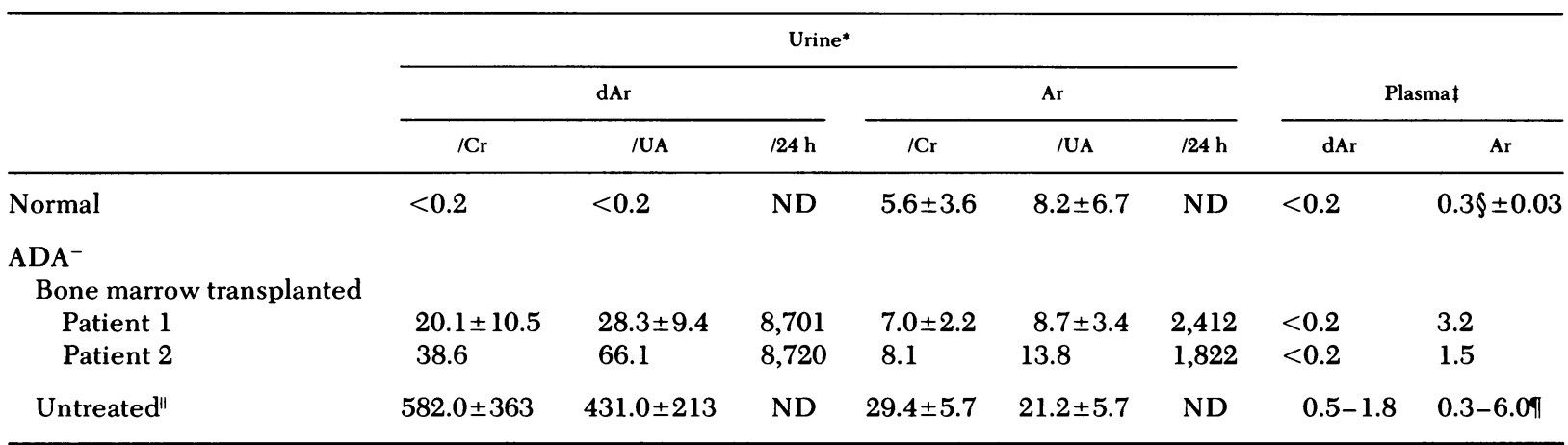

* Urinary nucleosides are reported as nanomoles per milligram $\mathrm{Cr}$ or UA and nanomoles/24 $\mathrm{h}$.

‡ Plasma nucleosides are reported in micromolar concentrations.

$\S$ Values for normal blood drawn in the presence of DCF. Normal plasma Ar without DCF $=0.03 \mu \mathrm{M}$ (see text).

|| References 11, 32, and unpublished observations; these values agree with previously published values $(6,9,10)$.

ๆ References 9,32 , and unpublished observations; values in erythrocyte transfused patients ranged up to $6 \mu \mathrm{M}$ Ar, and plasma $\mathrm{dAr}<0.2 \mu \mathrm{M}$.

Ar, adenosine; dAr, deoxyadenosine; Cr, creatinine; ND, not done; UA, uric acid. 
plasma from erythrocytes, extracted both and determined the distribution of radiolabel as determined by chromatography on DE81 paper (25). The majority of the added adenosine (Table III) was taken up into the erythrocytes and three-fourths of the intra-erythrocytic radioactivity was present as phosphorylated compounds $(50-70 \%$ of total label) while approximately one-fifth had been metabolized to inosine and hypoxanthine (15.8-22\% of total) and only a small percentage remained as adenosine. The plasma contained $8-13 \%$ of the total radioactivity, of which $\sim 60 \%$ was present as adenosine. The combined conversion of $\sim 20 \%$ of the total adenosine to inosine and hypoxanthine, in the presence of high concentrations of the potent ADA inhibitor DCF, could represent either $(a)$ less efficient and/or less rapid uptake of DCF than of adenosine into erythrocytes and therefore incomplete inhibition of ADA in erythrocytes; $(b)$ the activity of an additional serum aminohydrolase present in plasma of ADA-deficient children as well as normals that is less inhibitable by DCF (28) or (c) further

TABLE III

Distribution of $\left[{ }^{14} \mathrm{C}\right]$ Adenosine Added to Whole Blood in the Presence of DCF

\begin{tabular}{lcccc}
\hline & & \multicolumn{3}{c}{ Percentage of total cpm } \\
\cline { 3 - 5 } & Expt. & Erythrocytes & Plasma & Combined \\
\hline Phosphorylated & 1 & 53.4 & 0.4 & 53.8 \\
compounds & 2 & 67.0 & 0.5 & 67.5 \\
& 3 & 71.0 & 0.4 & 71.4 \\
Hypoxanthine & 1 & 22.0 & 4.3 & 26.3 \\
\& inosine & 2 & 15.8 & 3.3 & 19.1 \\
& 3 & 20.2 & 0.4 & 20.6 \\
Adenosine & 1 & 4.4 & 7.1 & 11.5 \\
& 2 & 3.7 & 7.3 & 11.0 \\
Total & 3 & 1.9 & 6.7 & 8.6 \\
& 1 & 87.4 & 12.6 & 99.6 \\
& 2 & 88.2 & 11.8 & 100.0 \\
& 3 & 91.9 & 8.1 & 100.0 \\
\hline
\end{tabular}

Values represent distribution in erythrocytes and plasma as percentage of total counts per minute recovered in three experiments (recovery of added counts was $104 \%$ of expected in all experiments). Freshly drawn blood $(3.755 \mathrm{ml})$ was mixed with a solution of $\mathrm{DCF}$ and $\left[{ }^{14} \mathrm{C}\right] \mathrm{adenosine}(245 \mu \mathrm{l})$ to give final concentrations of $\left[{ }^{14} \mathrm{C}\right]$ adenosine of $1 \mathrm{nmol} / \mathrm{ml}$ and of DCF of either $1 \mathrm{nmol} / \mathrm{ml}$ ( 1 ) or $2 \mathrm{nmol} / \mathrm{ml}$ ( 2 and 3). In experiment $3,\left[{ }^{14} \mathrm{C}\right]$ adenosine was added $20 \mathrm{~min}$ after the DCF. The erythrocytes (and leukocytes) were immediately separated from plasma by centrifuging for $1 \mathrm{~min}$ in a Beckman microfuge at $4^{\circ} \mathrm{C}$. The plasma and erythrocytes were then each extracted (Methods) and chromatographed with standard compounds and the relevant sections of the chromatogram counted in a liquid scintillation counter. Recovery of $\left[{ }^{14} \mathrm{C}\right]-$ adenosine was $104 \%$ of expected counts per minute in both experiments. metabolism of AMP to IMP to inosine and then hypoxanthine by the sequential action of AMP deaminase, 5'-nucleotidase, and nucleoside phosphorylase. Of these possibilities, less rapid uptake of DCF by intact erythrocytes and incomplete inhibition of ADA did not appear to play a significant role, since neither preincubation of blood with DCF for 20 min before addition of the radiolabeled adenosine nor doubling the concentrations of DCF had any significant effect on the percentage of adenosine converted to hypoxanthine and inosine. Our ability to quantitatively recover adenosine added to separated plasma suggests that the serum adenosine aminohydrolase activity does not play a significant role and that the radiolabeled inosine and hypoxanthine in plasma probably derived from intra-erythrocytic metabolism by the pathway suggested above.

All of these findings indicate that in the presence of DCF, the major route of metabolism of adenosine during processing of whole blood is by pathways not affected in ADA-deficient blood, i.e. by rapid uptake into erythrocytes with phosphorylation $(29,30)$ and subsequent metabolism of a proportion of the phosphorylated compounds to inosine and hypoxanthine via AMP deaminase, 5'-nucleotidase, and nucleoside phosphorylase. Additionally, we have found, in an ADA-deficient child in whom all erythrocytes had been replaced by ADA normal erythrocytes, that plasma adenosine concentration remained elevated at 1 and 2 $\mu \mathrm{M}$. Thus the presence of ADA normal erythrocytes was not sufficient to lower ex vivo plasma adenosine during processing even to the higher values observed in normal plasma when whole blood was processed in the presence of DCF. Finally, even if the hypoxanthine and inosine, which was produced from adenosine in the presence of DCF, reflects incomplete inhibition of ADA, this would account for only a $20 \%$ lowering of normal plasma adenosine during processing. Therefore, the concentrations of adenosine in plasma of the bone marrow transplanted ADA-deficient patients appear to be truly higher than that observed in normals, even with addition of DCF ( 1 and 3 vs. $0.3 \mu \mathrm{M}$ ) and in the range of untreated or exchange-transfused ADA-deficient patients.

SAH hydrolase. It has been reported that deoxyadenosine irreversibly inactivates the enzyme SAH hydrolase in vitro (3) and erythrocytes from untreated ADA-deficient patients do show markedly diminished SAH hydrolase activity (16). If adenosine and/or deoxyadenosine concentrations were increased in vivo in the bone marrow transplanted patients, we would expect to find a secondary inactivation of the enzyme SAH hydrolase. SAH hydrolase activity was diminished in erythrocytes of the bone marrow transplanted patients, but not in those of the sibling donor (Table IV). 
TABLE IV

Erythrocyte SAH Hydrolase Activity*

Normals $(n=5)$

$5.64 \pm 0.25$

ADA-deficient patients

Bone marrow transplanted

Patient 1

Patient 2

$0.88 \pm 0.06(n=3)$

1.02

Erythrocyte transfused

Patient 1

0.98

Patient 2

1.14

Sibling bone marrow donor

5.5

* Nanomoles per milligram hemoglobin per hour.

\section{DISCUSSION}

Chen et al. have previously reported that engraftment of an ADA-deficient infant with donor lymphoid cells was followed by a fall of previously elevated erythrocyte dATP (as measured to HPLC) to normal, the functioning of the patient's own lymphoid cells and a state of lymphoid chimerism (19). In the two bone marrow transplanted ADA-deficient patients reported here, all lymphocytes are currently of donor origin. Using a more sensitive enzymatic assay, we now find that erythrocyte dATP is still clearly greater than normal in these two patients, albeit $<10 \%$ of the dATP concentrations found in untreated ADA-deficient patients. We also find that deoxyadenosine is excreted in increased amounts and that plasma adenosine is in the same range as that seen in untreated patients. In contrast, plasma deoxyadenosine could not be detected. SAH hydrolase activity is also diminished in erythrocytes of our bone marrow transplanted patients, consistent with increased plasma adenosine and urinary deoxyadenosine. Deoxy ATP and "total deoxyadenosine" content of the mononuclear cells also appears to be slightly elevated. However, when the mononuclear cells are depleted of monocytes, the dATP content of the lymphocytes (which are of donor origin and contain ADA) is lower than that of the monocytes (which do not appear to be of donor origin) and approaches the normal range.

The observations reported here raise several questions. First, our results suggest that in vivo concentration of plasma adenosine in both normals and ADAdeficient patients may be considerably greater than those determined by conventional techniques. Ultrarapid sampling and separation techniques may allow for the determination of the absolute in vivo concentration of adenosine in both normal and ADA-deficient human plasma. Such studies would have bearing on evaluating the physiologic significance of the reported multiple effects of adenosine. Nonetheless, the plasma concentration of adenosine in bone marrow-transplanted patients does appear to be increased relative to normal as in untreated patients. The finding of elevated plasma adenosine in the bone marrowtransplanted patients in the face of normal immunological function, suggests that an action of adenosine at a cell surface lymphocyte adenosine receptor does not play a significant role in the pathophysiology of the immunodeficiency.

The studies reported indicate that lymphoid cell engraftment provides marked but not complete clearing of abnormal metabolites from nonlymphoid body compartments of ADA-deficient patients. The concentrations of metabolites reported here may provide a "bench mark" against which to monitor the appropriate dosage and biochemical efficacy of alternate therapies under study, such as exchange transfusions (12), in patients for whom no bone marrow donor is available.

\section{ACKNOWLEDGMENTS}

We should like to thank Dr. H. Colten and Dr. S. J. Latt for analysis of $\mathrm{Y}$ fluorescence in separated monocytes; Dr. A. Rubinstein for blood samples from the two erythrocyte transfused, ADA-deficient patients; and Parke-Davis for the gift of deoxycoformycin.

Supported by National Institutes of Health grant A110343 and National Foundation 6-4.

\section{REFERENCES}

1. Giblett, E. R., J. E. Anderson, F. Cohen, B. Pollara, and H. J. Meuwissen. 1972. Adenosine deaminase deficiency in two patients with severely impaired cellular immunity. Lancet. II: 1067-1069.

2. Meuwissen, H. J., B. Pollara, and R. J. Pickering. 1975. Combined immunodeficiency disease associated with adenosine deaminase deficiency.J. Pediatr. 86: 169-181.

3. Hirschhorn, R. 1977. Defects of purine metabolism in immunodeficiency diseases, In Progress in Clinical Immunology. R. S. Schwartz, editor. Grune \& Stratton, Inc. New York. Vol. III: 67-83.

4. Mills, G. C., F. C. Schmalstieg, K. B. Trimmer, A. S. Goldman, and R. M. Goldblum. 1976. Purine metabolism in adenosine deaminase deficiency. Proc. Natl. Acad. Sci. U.S.A. 73: 2867-2876.

5. Schmalstieg, F. C., J. A. Nelson, G. C. Mills, T. M. Monahan, A. S. Goldman, and R. M. Goldblum. 1977. Increased purine nucleotides in adenosine deaminasedeficient lymphocytes. J. Pediatr. 91: 48-51.

6. Simmonds, H. A., A. Sahota, C. F. Potter, and J. S. Cameron. 1978. Purine metabolism and immunodeficiency: urinary purine excretion as a diagnostic screening test in adenosine deaminase and purine nucleoside phosphorylase deficiency. Clin. Sci.Mol. Med. 54: 579-584.

7. Cohen, A. R., R. Hirschhorn, S. D. Horowitz, A. Rubinstein, S. H. Polmar, R. Hong, and D. W. Martin, Jr. 1978. Deoxyadenosine triphosphate as a potentially toxic metabolite in adenosine deaminase deficiency. Proc. Natl. Acad. Sci. U.S.A. 75: 472-476.

8. Coleman, M. S., J. Donofrio, J. J. Hutton, L. Hahn, A. Daoud, B. Lampkin, and J. Dyminski. 1978. Identification 
and quantitation of adenine deoxynucleotides in erythrocytes of a patient with adenosine deaminase deficiency and severe combined immunodeficiency. J. Biol. Chem. 253: $1619-1626$.

9. Hirschhorn, R., V. Roegner, A. Rubinstein, and P. Papageorgiou. 1980. Plasma deoxyadenosine, adenosine, and erythrocyte deoxy-ATP are elevated at birth in an adenosine deaminase-deficient child. J. Clin. Invest. 65: 768-771.

10. Kuttesch, J. F., F. C. Schmalstieg, and J. A. Nelson. 1978. Analysis of adenosine and other adenine compounds in patients with immunodeficiency diseases. J. Liq. Chrom. 1: $97-109$.

11. Hirschhorn, R., P. Papageorgiou, A. Rubinstein, and F. S. Rosen. 1979. Transfusion vs. bone marrow transplantation in combined immunodeficiency. Clin. Res. 27: 507a.

12. Polmar, S. H., R. C. Stern, A. L. Schwartz, E. M. Wetzler, P. A. Chase, and R. Hirschhorn. 1976. Enzyme replacement therapy for adenosine deaminase deficiency and severe combined immunodeficiency. N. Engl. J. Med. 295: $1337-1343$.

13. Green, H., and T.-S. Chan. 1973. Pyrimidine starvation induced by adenosine in fibroblasts and lymphoid cells: role of adenosine deaminase. Science (Wash. D. C.). 182 : 836-837.

14. Planet, G., and Fox, I. H. 1976. Inhibition of phosphoribosyl pyrophosphate synthesis by purine nucleosides in human erythrocytes. J. Biol. Chem. 251: 58395844 .

15 Wolberg, G., T. P. Zimmerman, K. Hemstra, M. Winston, and L.-C. Chu. 1975. Adenosine inhibition of lymphocytemediated cytolysis: possible role of cyclic adenosine monophosphate. Science (Wash. D. C.). 187: 957-959.

16. Hershfield, M. S., N. M. Kredich, D. R. Ownby, H. Ownby, and R. Buckley. 1979. In vivo inactivation of erythrocyte $\mathrm{S}$-adenosyl homocysteine hydrolase in adenosine deaminase-deficient patients. J. Clin. Invest. 63: 807-811.

17. Schwartz, A. L., R. C. Stern, and S. H. Polmar. 1978 Demonstration of an adenosine receptor on human lymphocytes in vitro and its possible role in the adenosine deaminase-deficient form of severe combined immunodeficiency. Clin. Immunol. Immunopathol. 9: 499-505.

18. Parkman, R., E. W. Gelfand, F. S. Rosen, A. Sanderson, and R. Hirschhorn. 1975. Severe combined immunodeficiency and adenosine deaminase deficiency. N. Engl. J. Med. 292: 714-719.

19. Chen, S.-H., H. D. Ochs, C. R. Scott, E. R. Giblett, and A. J. Tingle. 1978. Disappearance of adenine nucleotides from a patient's erythrocytes after successful marrow transplantation. J. Clin. Invest. 62: 1386-1389.

20. Hoffman, J. L. 1978. Biosynthesis of $\mathrm{S}-\mathrm{N}^{6}$ methyl adenosine homocysteine.J. Biol. Chem. 253: 2905-2907.
21. Solter, A. W., and R. E. Handschumacher. 1969. A rapid quantitative determination of deoxyribonucleoside triphosphate based on the enzymatic synthesis of DNA. Biochim. Biophys. Acta. 174: 585-590.

22. Khym, J. X. 1975. An analytical system for rapid separation of tissue nucleotides at low pressure on conventional anion exchangers. Clin. Chem. 21: 1245-1252.

23. North, T. W., R. K. Bestwick, and C. K. Mathews. 1980. Detection of activities that interfere with the enzymatic assay of deoxyribonucleoside $5^{\prime}$ triphosphate. J. Biol. Chem. 255: 6640-6645.

24. Hershfield, M. S. and N. M. Kredich. 1980. Resistance of an adenosine kinase-deficient human lymphoblastoid cell line to effects of deoxyadenosine on growth, S-adenosyl homocysteine hydrolase inactivation, and dATP accumulation. Proc. Natl. Acad. Sci. U. S. A. 77: 4292-4296.

25. Coleman, M. S. and J. J. Hutton. 1975. Micromethod for quantitation of adenosine deaminase activity in cells from human peripheral blood. Biochemistry. 12: 46-55.

26. Hirschhorn, R., V. Roegner, T. Jenkins, C. Seaman, S. Piomelli, and W. Borkowsky. 1979. Erythrocyte adenosine deaminase deficiency without immunodeficiency: evidence for an unstable mutant enzyme.J. Clin. Invest. 64: 1130-1139.

27. Donofrio, J., M. S. Coleman, and J. J. Hutton. 1978. Overproduction of adenine deoxynucleosides and deoxynucleotides in adenosine deaminase deficiency with severe combined immunodeficiency disease. J. Clin. Invest. 62: 884-887.

28. Ratech, H., and R. Hirschhorn. 1981. Serum adenosine deaminase in normals and a patient with adenosine deaminase deficient-severe combined immunodeficiency. Clin. Chim. Acta. In press.

29. Lum, C. T., R. Marz, P. G. W. Plagemann, and R. M. Wohlhueter. 1979. Adenosine transport and metabolism in mouse leukemia cells and in canine thymocytes and peripheral blood leukocytes. J. Cell Physiol. 101: $173-200$

30. Marz, R., R. M. Wohlheuter, and P. G. W. Plagemann. 1979. Purine and pyrimidine transport and phosphoribosylation and their interaction in overall uptake by cultured mammaliean cells: a reevaluation. J. Biol. Chem. 254: 2329-2338.

31. Hershfield, M. S. 1979. Apparent suicide inactivation of human lymphoblast S-adenosyl homocysteine hydrolase by 2 -deoxyadenosine and adenine arabionsine. J. Biol. Chem. 254: 427-435.

32. Hirschhorn, R., H. Ratech, A. Rubinstein, P. Papageorgiou, H. Kesarwala, E. Gelfand, and V. RoegnerManiscalco. 1981. Increased excretion of modified adenine nucleosides by children with adenosine deaminase deficiency. Pediatr. Res. In press. 